\title{
Cytogenetic Analysis
}

National Cancer Institute

\section{Source}

National Cancer Institute. Cytogenetic Analysis. NCI Thesaurus. Code C18280.

Techniques for analysis of chromosomal and subchromosomal properties and

structures, such as those to diagnose, classify, screen for, or manage genetic diseases and abnormalities. 